\title{
ACERCA DEL DESARROLLO DE LAS CIENCIAS SOCIALES*
}

Fernando Durán P.

En 1972, cuando el rector Edgardo Boeninger dictó el decreto de creación de la Facultad de Ciencias Sociales de la Universidad de Chile, los profesores de esta Facultad, que habíamos participado en los prolongados debates de una década para llegar a ese momento, sentimos que se cumplía una etapa histórica en el desenvolvimiento de nuestras disciplinas.

En efecto, es una tendencia mundial del desarrollo universitario el que las Ciencias Sociales den sus primeros pasos al amparo de las Facultades de Filosofía o de Derecho y, luego, alcanzado cierto nivel de madurez, se independicen para consolidarse como un campo distintivo del saber al que formalmente se asigna un lugar propio, reconociéndose a sus especialistas no sólo la natural prerrogativa de fijar los estilos más apropiados para el cultivo de sus disciplinas, sino también la capacidad de determinar las políticas institucionales más convenientes para el progreso de ese campo conforme a sus particulares características.

Nuestras esperanzas de entonces se cumplieron sólo parcialmente. En los años siguientes, la naciente Facultad afrontó sucesivas reorganizaciones realizadas sin tuición de nuestros académicos en 1973, 1976 y 1981, año en que se suprimió legalmente la Facultad por la misma normativa que terminó con la formación pedagógica en la Universidad de Chile, hecho de tal resonancia nacional que la supresión de nuestra Facultad pasó inadvertida. Las Ciencias Sociales, incluyendo ahora a la Educación, quedaron dependiendo de la Facultad de Filosofía, sujetas a nuevos cambios como la reorganización de 1985; hasta que la voluntad del cuerpo

* Exposición ante el Primer Encuentro de Especialistas de Ciencias Sociales y Humanidades de la Universidad de Chile, Salón de Honor de la Corporación, 22 de octubre de 1990. 
académico obtuvo revertir la medida legal de 1981, constituyéndose nuevamente la Facultad de Ciencias Sociales en 1989.

Es indudable que las continuas reorganizaciones, con su secuela de cambio de localización física, de reglamentación y planes de estudios, de estructuras y autoridades, y de progresivas reducciones presupuestarias, crearon condiciones muy adversas para que las Ciencias Sociales pudieran definir objetivos de conjunto $y$ lograr la concertación de acciones de sus diversas unidades para alcanzar tales objetivos comunes.

En ese marco de inestabilidad y limitaciones, sin embargo, los académicos de Ciencias Sociales han sido protagonistas de un extraordinario esfuerzo de continuidad del quehacer académico de estas disciplinas. Los profesores de los Departamentos de Antropología, de Ciencias de la Comunicación, de Educación, de Psicología y de Sociología, lograron en ese período lo que no se consiguió en otras Universidades incluso dotadas de mayor estabilidad: mantener la presencia institucional de nuestras disciplinas en la Universidad de Chile y, desde aquí, sostener el desenvolvimiento de las Ciencias Sociales en el país.

Esa actividad se materializó en importantes proyectos de investigación, en una sostenida línea de publicaciones científicas, en la mantención de una labor formadora conducente a licenciaturas y títulos profesionales que fue enriquecida por la puesta en marcha de programas de postgrado pioneros en nuestro país.

La continuidad del quehacer académico de las Ciencias Sociales en la Universidad de Chile hizo posible captar más vocaciones para estas ciencias y las profesiones respectivas, respaldar institucionalmente el ejercicio de los profesionales del área a lo largo de todo Chile, y obtener que este campo del saber preserve su legitimidad dentro del sistema universitario como un dominio que genera conocimiento científico básico y aplicado de gran significación social.

A pesar de todo lo hecho, existe consenso entre nosotros, antropólogos, arqueólogos, periodistas, educadores, psicólogos y sociólogos, acerca de que nuestro campo científico y profesional no ha alcanzado todavía el rol decisivo que consideramos debería jugar en la Universiad y en el país.

Para las Ciencias Sociales, vemos el futuro como posibilidad abierta a la imaginación y la voluntad de sus especialistas. Si nuestro objetivo es asegurar la presencia de las Ciencias Sociales en la Universidad de Chile con un rango institucional y una autonomía operativa suficientes para decidir con independencia el destino de este campo del saber, lograr en plenitud ese objetivo nos exige imprimir a la marcha de la Facultad un sentido y ritmo de desenvolvimiento conducente al mejor aprovechamiento de su potencial académico.

Es decir, hay que diseñar e implementar una política de Facultad que tenga un sentido explícito de desarrollo, y no solamente de continuidad de lo ya hecho. Eso, como es obvio, requiere revisar los principios orientadores que fueron eficaces para responder a los desafíos del pasado inmediato. 
Esto no es solamente porque quisiéramos ver a nuestra Facultad expandirse y asumir un papel más destacado en la creación y transmisión del saber. Es también porque creemos que el vuelco desde una política de continuidad hacia una política de desarrollo, es imperativo para mantener la posición y niveles de actividad que poseemos.

Entramos a la década de los noventa como una entidad que tiene otras características y que se inscribe en una realidad nacional distinta a los años precedentes. Hoy nuestros profesores son más conscientes de que el ejercicio adecuado de sus deberes académicos exige como correlato hacer efectivo sus derechos; tenemos alumnos más críticos sobre la preparación que reciben; encontramos universidades privadas en rápido crecimiento que irrumpen en nuestras áreas; los recursos fiscales que financian al sistema universitario son limitados y en parte se asignan sobre bases competitivas; $y$, por sobre todo, somos parte de una nación que espera de las Ciencias Sociales que sean guia objetiva y eficiente para planear su progreso social. Pues bien, planteada la marcha futura de la Facultad en una óptica de desarrollo, los aspectos mencionados tienen signo positivo para dinamizar nuestra actividad; sin esa perspectiva, todos ellos son fuente de tensiones que no podemos manejar.

Lo esencial, antonces, es proponer las lineas directrices en torno a las cuales debe darse ese desarrollo de las Ciencias Sociales. Es decir, una definición académica, que se constituya en concepción orientadora para guiar las decisiones operacionales.

En el ánimo de contribuir a esa definición, me permito sugerir que un centro de gravedad apropiado para el desarrollo de las Ciencias Sociales en la Universidad de Chile se obtendria al encauzar nuestro quehacer hacia el estudio de aquellos temas que en nuestra situación nacional tienen un valor fundamental. Consideramos tarea prioritaria de nuestra Facultad, promover una acumulación rápida de conocimientos en este campo del saber que, ajustándose a las exigencias del método científico, ofrezcan una referencia directa a nuestra realidad social y sus problemas.

Aquí, en el ámbito de la conducta humana que se nos da como realidad inmediata, casi todo a nuestro alrededor está por explorar, casi todo es inédito. Es deber de las Ciencias Sociales y sobre todo de los universitarios que en ellas laboran, hacer inteligibles los problemas de nuestra sociedad y aportar soluciones. Desde luego, no se trata de obtener conocimientos para una ingeniería conductual a la manera de B.F. Skinner. Se quiere un conocimiento aplicable, sí, pero plenamente consciente de sus responsabilidades y límites, o sea, ética y epistemológicamente lúcido.

El deseo de aplicar los mejores instrumentos de la ciencia para entender y mejorar las circunstancias concretas de nuestra vida nacional, es parte integral de la tradición de la Universidad de Chile. Está contenido en el discurso inaugural del rector Andrés Bello y, con referencia más próxima a nuestra temática, está presente 
en el pensamiento del rector Valentín Letelier, para mencionar dos hitos trascendentes en lo que ha sido postura permanente de esta casa de estudios.

Nuestra propuesta es retomar ese legado de preocupación prioritaria por los problemas nacionales $y$, con renovada energía intelectual, hacerlo hilo conductor para el desarrollo de las Ciencias Sociales en nuestra Universidad.

Quizás sea oportuno añadir algunas precisiones para una comprensión cabal de lo propuesto.

Ante todo, dejar constancia que la búsqueda de conocimiento que se menciona, no discurre sólo por los caminos de lo que a veces restrictivamente denominamos investigación. Esa búsqueda puede ser igualmente rigurosa en la indagación que es diálogo de primera mano con los hechos empíricos, o en la reconstrucción intelectual del saber en el aula en diálogo reflexivo con las inquietudes del alumno. La ciencia misma en acto creador actuando simultáneamente en el avance y en la transmisión del conocimiento: he aquí la concepción de J.T. Fichte en su célebre plan de enseñanza superior, documento fundacional para la renovación de la Universidad alemana.

Enseguida, aclaremos que poner énfasis en el conocimiento científico de nuestra propia realidad no quiere decir abordar esa tarea como parte segregada en busca de teorías particulares para nuestro entorno, sino en función del sentido que le da su permanencia al sistema total del conocimiento. Qué duda cabe, por ejemplo, que al centrar nuestra atención en los efectos sociales que tienen en nuestro ambiente los medios de comunicación masiva, el diseño de nuestras investigaciones tendrá que apoyarse en todo el instrumental teórico y metodológico que han elaborado las Ciencias Sociales para examinar ese problema en otras latitudes; como también es indudable que los hallazgos relativos a nuestra realidad tendrán impacto retroalimentador en los modelos teóricos y estilos de investigación foránea.

Luego, anotemos que basta mencionar temas cuyo análisis las Ciencias Sociales deben abordar en nuestro país, para ver que una correcta aproximación trasciende al especialista singular. Al decir de K. Mannheim, los especialistas de estas disciplinas tendrán que acostumbrarse a un modo de pensamiento interdependiente. Efectivamente, si nos preocupa el tema de la pobreza y la marginalidad social, será preciso acudir al antropólogo para que examine las redes de apoyo comunitario que son características del respectivo sistema cultural; al comunicador, para analizar las formas de comunicación no verbal que los sectores marginales manejan; al educador, quien considera los modos diferenciales de socialización en esos grupos; al psicólogo, para estudiar el deterioro de la identidad individual; al sociólogo, para discernir los estilos de liderazgo en situaciones de marginalidad. Al considerar los problemas concretos de nuestra sociedad, la visión es necesariamente multidimensional $y$, por ende, multidisciplinaria.

Otro comentario se relaciona con los nexos entre ciencia pura y aplicada. Todos 
sabemos que las fronteras entre ambos tipos de conocimiento son ambiguas y a menudo indefinibles. Pero es interesante destacar cuán fructífera es la interpenetración de ambos momentos del quehacer científico cuando nos ocupamos de problemas concretos de la conducta humana en un contexto definido. Pensemos, por ejemplo, en los niveles de aspiraciones educacionales de nuestra juventud, tema crucial para el planeamiento educativo. La conocida teoría de H.S. Sullivan sobre los "otros-significativos", individuos referenciales que influyen sobre la formación de esas aspiraciones en el joven, tendrá que ser revisada como un posible instrumento de interpretación; $y$ en ese proceso será evaluada su potencia explicativa y sus necesidades de reformulación, a la luz del ensayo de su aplicación a nuestra realidad.

Para terminar, quisiera referirme al espíritu con que el especialista de las Ciencias Sociales debe asumir el estudio de la realidad que lo circunda. Un reconocido investigador experimental en nuestro campo. A. Maslow, nos dice que la actividad científica ha llegado a identificarse con la precaución, la paciencia, el no cometer errores, la prueba repetida infinitamente; una actitud que no tiene mucho que ver con el espíritu de aventura, riesgo e innovación que históricamente ha producido los mayores avances de la ciencia. Creemos que el intento por adelantar la búsqueda de conocimientos sobre nuestra propia realidad social, por la naturaleza inédita de los problemas que tendremos que abordar y por las limitaciones de nuestros medios para hacerlo, exigirá de nosotros mucho más de ese espíritu de aventura, que del rutinario ejercicio que Maslow critica. 